\title{
Recognition of facial expressions in children, young adults and elderly people
}

\author{
Reconhecimento de expressões faciais \\ em crianças, jovens e idosos
}

\author{
Jamila Leão LEIME \\ Júlio RIQUE NETO \\ Simone Marin ALVES \\ Nelson TORRO-ALVES
}

\begin{abstract}
The present study evaluated the recognition of facial expressions in different ages, using groups composed of: 1) 21 children with a mean age of 7.7 years; 2) 19 young adults with a mean age of 20.1 years; and 3) 9 elderly people with a mean age of 74.7 years. In the tests, participants were asked to identify facial expressions of happiness, sadness, fear and anger of different emotional intensities. The results indicated that the young adults performed better in recognizing facial expressions when compared to the children and elderly people. The children presented a performance similar to the elderly people, supporting the hypothesis that the ability to recognize facial expressions improves in adulthood and diminishes in old age.
\end{abstract}

Uniterms: Development; Emotion; Facial expressions; Perception.

\section{Resumo}

Desenvolveu-se um estudo para avaliar r reconhecimento de expressões faciais em diferentes faixas etárias, com inclusão de grupos compostos por: 1) 21 crianças com idade média de 7,7 anos;2) 19 adultos jovens com idade média de 20,1 anos; e 3) 9 idosos com idade média de 74,7 anos. Na situação de teste, foi solicitado aos participantes que identificassem expressões faciais de alegria, tristeza, medo e raiva em diferentes intensidades emocionais. Os resultados indicaram que os jovens apresentaram um melhor desempenho no reconhecimento de expressões faciais, quando comparados a crianças e idosos. Crianças apresentaram um desempenho similar aos idosos, apoiando a hipótese de que as capacidades de reconhecimento de expressões faciais aperfeiçoam-se na idade adulta e diminuem na velhice.

Unitermos: Desenvolvimento; Emoção; Expressões faciais; Percepção.

The ability to quickly capture and interpret emotional cues in the social environment allows people to anticipate events and respond appropriately to them
(Isaacowitz et al., 2007). Within this perspective, it is observed that humans develop the ability to recognize emotions in facial expressions very early in life.

$\operatorname{rrv}$

- Universidade Federal da Paraíba, Centro de Ciências Humanas Letras e Artes, Departamento de Psicologia. Cidade Universitária, Conjunto Humanístico, Bloco IV, 58059-900, João Pessoa, PB, Brasil. Correspondência para/Correspondence to: N. TORRO-ALVES. E-mail: <nelsontorro@yahoo.com.br>.

Support: Conselho Nacional de Desenvolvimento Científico e Tecnológico (Grant n 575284/2008-0/Edital 33/2008). 
Studies from evolutionary psychology and cognitive neuroscience have indicated a different nature of facial recognition, suggesting that faces are perceived as a special class of stimuli, different from other categories of objects (Keightley, Chiew, Winocur \& Grady, 2007; Nelson, 2001). The appraisal of the social environment, as well as the establishment of interpersonal relationships, depends largely on the proper recognition of facial expressions (Ekman, 1999; Zebrowitz \& Montepare, 2008). In this sense, there has been much discussion about the role of the recognition of facial expressions in the social context (Biele \& Grabowska, 2006; Ebner \& Johnson, 2009; Thomas, De Bellis, Graham $\&$ LaBar, 2007) and the emotional development of the individual (Ko, Lee, Yoon, Kwon \& Mather, 2011).

Some authors claim that the perceptual structure of facial expressions remains similar from childhood to adulthood and is organized in two dimensions: pleasure-displeasure and activation-deactivation (Gao, Maurer \& Nishimura, 2010). Meanwhile, other studies argue that the ability to identify facial expressions improves with age (Fox, 2001; Herba \& Phillips, 2004; Thomas et al., 2007).

To explain this improvement throughout development, the authors believe that there is a progressive increase in the ability to identify configurational properties of faces. Maurer, Le Grand and Mondloch (2002) distinguished these properties as: 1) First-order (relative position of the elements of the face such as eyes positioned above the nose), 2) Secondorder (rotation and distance between the elements of the face) and 3) Holistic (the facial features perceived in a single gestalt in an integrated way). The authors concluded that a change in the spatial pattern of faces (placing them upside down or changing the rotation of elements, such as the eyes and mouth) interferes in the recognition of facial expressions. In agreement with the hypothesis of the configurational properties, neuropsychological studies in adults have shown that normal recognition capability is reduced when faces are presented upside down (Farah, Tanaka \& Drain, 1995; Valentine, 1988).

Some authors state that throughout development the recognition of positive emotions precedes the identification of negative emotions (Widen \& Russell, 162 2003). Conversely, Durand, Gallay, Seigneuric, Robichon and Baudouin (2007) argue that the increase in the capacity for identifying facial expressions of sadness and joy occurs concomitantly. According to this concept, at around five or six years of age, performance in recognizing emotions of joy and sadness would be similar to adults. The authors also found that the ability to recognize facial expressions of fear only equals the adult ability at around seven years of age, whist the ability to recognize the emotions of anger and disgust, reaches its optimal level between nine and eleven years of age.

Although there is evidence in favor of an increase in the recognition of facial expressions in adolescence (Thomas et al., 2007), some authors have reported a decline in the recognition of facial expressions throughout development. The evidence is corroborated by studies that verify a decline of performance in the recognition of negative emotions from late adulthood on (Grady, Hongwanishkul, Keightley, Lee\&Hasher, 2007).

In view of the discrepancies reported in the literature, and considering the lack of studies investigating the recognition of facial expressions throughout development, the present study aimed to evaluate the perception of facial expressions in three age groups. For this purpose, groups were composed of children, young adults and elderly people who judged facial expressions of happiness, sadness, fear and anger in different emotional intensities. One of the main advantages of using emotional expressions of different intensities is to ascertain how individuals evaluate subtle facial expressions that occur with relative frequency in the environment of social interaction.

In this study, we started with the assumption that there would be an increase in facial expression recognition rates in early adulthood, followed by a possible decline in old age. We also carried out a comparative analysis between the recognition rates of the four emotions investigated according to the different stages of development.

\section{Method}

\section{Participants}

Participants were divided into three age groups. The first group was composed of 21 children (10 boys, 
11 girls), students of a public school, participating in a program of continuing education in the city of João Pessoa, Paraíba (PB), in Brazil, aged between six and eight years (Mean age - $M=7.7$, Standard Deviation - SD=0.7 years). The second group was composed of 19 young adults (7 men, 12 women), students of the Universidade Federal da Paraiba (UFPB), aged between 18 and 25 years ( $M=20.10, S D=2.0$ years). The third group was composed of nine elderly people (three men, six women) residents of a nursing home in João Pessoa (PB), aged between 65 and 83 years $(M=74.7$ years, $S D=6.9$ years). The study was approved by the Ethics Committee of the UFPB, under protocol n 0167, on 27/5/2009, and all participants or guardians signed the terms of free prior informed consent before participation.

\section{Materials}

The present study used NimStim Face Stimulus Set (Tottenham, Borscheid, Ellertsen, Marcus \& Nelson, 2002), currently available at <http://www.macbrain.org/ faces/index.htm>. The NimStim Face Stimulus Set consists of color photographs of people of different ethnicities depicting faces with emotional expressions and neutral faces. For the present study, we used the images of two women (models 1 and 16) and two men (models 37 and 41) outlining expressions of happiness, sadness, fear, anger and a neutral expression. Each picture had a resolution of $506 \times 650$ pixels in a Red, Green, Blue (RGB) color pattern.

The original faces were manipulated to produce intermediate levels of emotional intensity through the morphing technique. The intensity is determined by the amount of relaxation of the facial muscles, when compared to a neutral emotional state. We generated six intermediate levels of intensity between the neutral face (0.0\%) and emotional faces (100.0\%), with the levels corresponding to $14.3 \%, 28.5 \%, 42.8 \%, 57.1 \%, 71.4 \%, 85.7 \%$ and $100.0 \%$ of maximum emotional intensity. Morphing effects were generated with the Morpheus Photo Animation Suite (version 3.10) program and the Adobe Photoshop (CS3 10.0) program was used to attenuate distortions in the photographs.

In the present study, we used expressions with intermediate $(42.8 \%, 57.1 \%)$ and high values of emotional intensity (71.4\%, 85.7\% and 100.0\%). Subtle expressions with values 14.3\%, 28.5\% were not included in this study because they are extremely difficult to recognize and substantially increase the duration of the recognition sessions. Thus, a total of 80 pictures were obtained from the morphing construction ( 4 models $x$ 4 emotions $\times 5$ intensities). The photographs were printed on mat paper size $15 \times 21 \mathrm{~cm}$ (width $\times$ height) (Figure 1).

\section{Identification of photographs}

Each photograph received a three-digit identification code on the back, allowing the computation of the subsequent responses of the subjects. The first digit represented the model number. The second digit identified the emotion outlined in the photo (happiness, sadness, fear or anger). The third digit identified the intensity of emotion. A standardized table was used to record the participant's responses.

\section{Procedures}

Tests were applied individually and the participants were instructed to look carefully at the

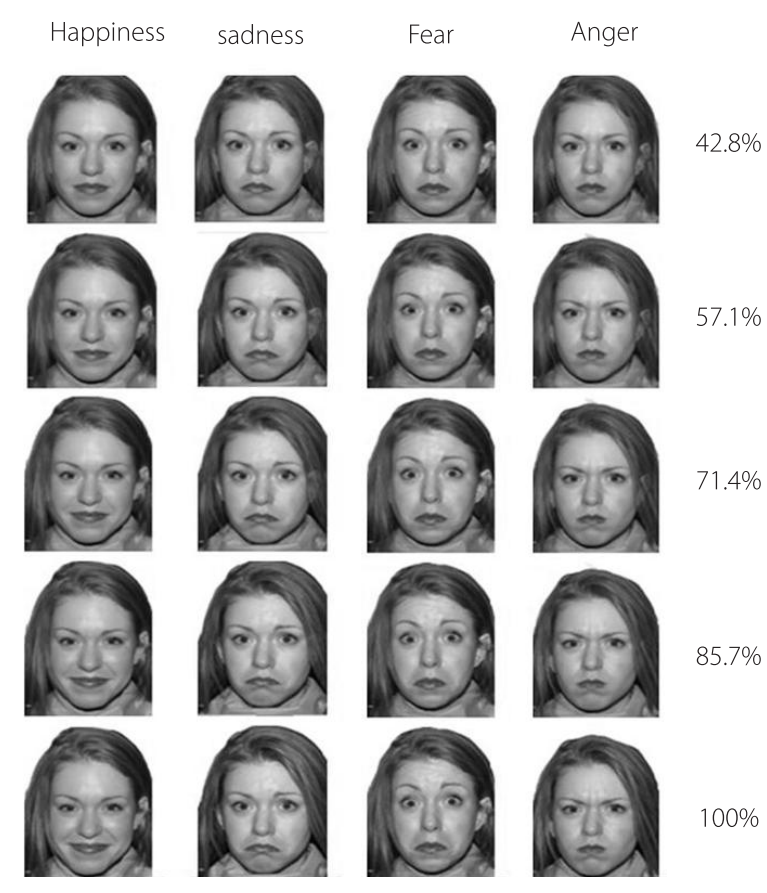

Figure 1. Emotional faces produced by the morphing technique. Faces varied at a rate of $14.29 \%$ in emotional intensity. Note: Original images were taken from NimStim Face Stimulus Set (Tottenham et al., 2002), with permission of the authors. 
photographs and to identify which emotion among the four (happiness, sadness, fear or anger) was expressed on the face. The researcher recorded the participant's responses on a standardized table, writing the code of the photograph in the column of the emotion chosen by the participant. Each participant was identified by a number. At the end of the test application the responses were tabulated.

Test procedures were adapted to the different groups of the study. For the groups composed of young and old adults, the pictures were randomly presented and the participants were instructed to examine them carefully and then to record the emotion expressed by the face.

In order to make the task of recognizing facial expressions less tiring for the children, the procedures were adapted according to Gao and Maurer (2009). For the experimental session, children were taken individually to a room in which they found a table. On the table, there were four dollhouses. In the front of each house there was a figure depicting schematic expressions of happiness, sadness, fear or anger.

The experimenter then asked the child, "inside each one of these houses there are people telling stories of happiness, sadness, fear or anger. Could you tell me which story is being told in each one?". If the child identified the emotion presented for each house correctly, the researcher proceeded to the next step, saying: "Now I'll show you photographs of people with different emotions and you should help them to reach their home. A person can only enter a home if it contains people who feel the same as him or her. Is that ok?". After the experimenter certified that the child had understood the instructions correctly, the photos were presented one at a time and the child was asked to place each photo in a matching house according to the facial expressions depicted in the photograph.

\section{Results}

Rates of recognition for each emotion were analyzed using a repeated measures Analysis of Variance (Anova) model: 3 groups of participants (children, young 164 adults and elderly people) x [4 emotions (happiness, sadness, fear and anger) $\times 5$ intensities (42.8\%, 57.1\%, $71.4 \%, 85.7 \%$ and $100.0 \%)]$.

Results showed statistically significant effects for age $\left(F_{2,46}=21.02, p=0.001\right)$, emotion $\left(F_{3,44}=55.56, p=0.001\right)$ and intensity ( $\left.F_{4,43}=4.20, p=0.001\right)$. Tukey's post-hoc test revealed that the group of young adults outperformed the groups of children and elderly people in the facial expressions recognition test $(p<0.001)\left(M_{\text {young adults }}=91.91\right.$, $S D=6.01)$, whereas the children and elderly people presented similar patterns of performance $(p>0.05)$ $\left(M_{\text {children }}=74.34, S D=8.79 ; M_{\text {elderly }}=71.80, S D=14.69\right)$ (Figure 2).

The emotion of happiness had the highest mean recognition rate for the children $\left(M_{\text {children/joy }}=98.57\right.$, $\mathrm{SD}=4.60)$ : young adults $\left(\mathrm{M}_{\text {young adults/joy }}=98.95, \mathrm{SD}=4.40\right)$ and elderly ( $\left.M_{\text {elderly/joy }}=95.00, S D=13.69\right)$ groups. The emotion of sadness had the lowest rate in the three groups ( $M_{\text {children/ }}$ sadness $=50.00, S D=14.26 ; M_{\text {young adults/sadness }}=87.89, \mathrm{SD}=13.94$; $\left.M_{\text {elderly/sadness }}=59.44, \mathrm{SD}=28.35\right)$. The emotions of fear and anger presented high rates of recognition especially in the young adult group ( $M_{\text {young adult/fear }}=90.53, S D=12.37$; $\left.M_{\text {youngadult/anger }}=90.26, S D=13.17\right) ;$ and in the elderly group the rates were lower $\left(M_{\text {elderly/fear }}=66.67, S D=30.15 ; M_{\text {elderly/ }}\right.$ anger $=66.11, S D=24.51$ ) suggesting a difficulty in differentiating the facial features that distinguish these emotions. The group of children presented a recognition

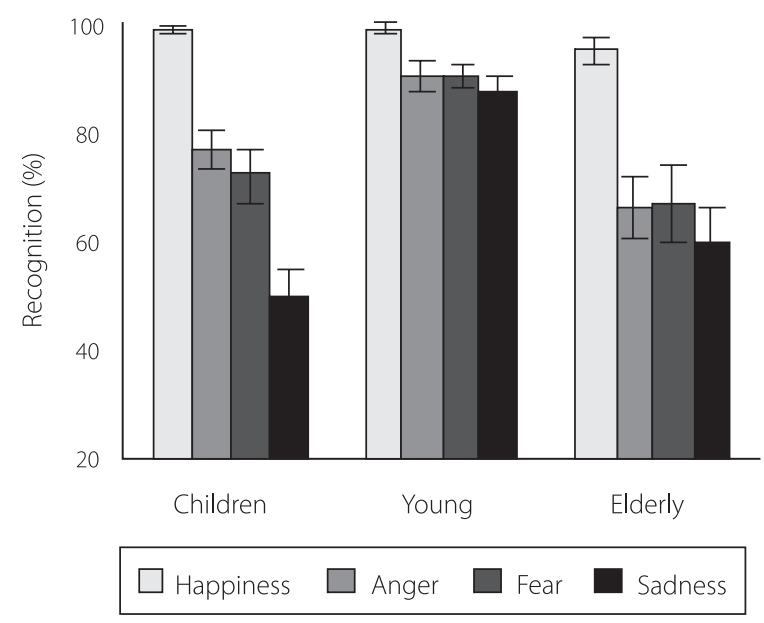

Figure 2. Recognition of emotions of low intensity $(42.8 \%$ and $57.1 \%)$.

Note: Young adults presented better performance in the recognition of subtle emotions when compared to the children and elderly people. The emotion of happiness was recognized more precisely than other emotions. 
rate of the emotion of fear of $72.14 \%$ (SD=9.20) and anger of $76.67 \%$ (SD=16.79) (Figure 2).

Tukey's post-hoc test revealed that facial expressions with less emotional intensity $(42.8 \%$ and $57.1 \%)$ were recognized by the groups with greater difficulty and the accuracy rate of recognition of these expressions were similar between the children $\left(M_{\text {children }}=67.71, S D=6.10\right)$ and elderly $\left(M_{\text {elderly }}=61.80\right.$, $\mathrm{SD}=2.95$ ) groups. In the young adult group this index was 88.98 ( $(\mathrm{D}=3.49)$ and, although it was the lowest success rate in this group, this finding corroborates the evidence for the greater ability of young adults to recognize expressions with low thresholds.

Pearson's correlation was performed to determine the influence of age on the recognition of facial expressions. The results showed a significant and positive correlation between the group of children and the recognition of sadness $(r=0.45, p<0.05)$ suggesting that the recognition of sadness increases with age. In the other two groups of participants (young adults and elderly people), the variable age appeared to have little influence on the recognition of facial expressions.

\section{Discussion}

The present study investigated the recognition of facial expressions of happiness, sadness, fear and anger into three age groups: children, young adults and elderly people. Photographs with different intensities of each emotion were used for this purpose. We observed that the children and the elderly people showed similar rates of recognition of emotions, which coincides with the observations of Grady et al. (2007).

This similarity supports the idea that the perception of emotions in facial expressions develops in childhood, reaches its optimal state in youth, and eventually starts to decline in old age. Moreover, the young adult group was more sensitive in the perception of these emotions, even when presented at low intensities, presenting superior performance compared to the children and elderly people.

Accordingly to results found in other studies (Ebner \& Johnson, 2009; Gao \& Maurer, 2009; Palermo \& Coltheart, 2004), the emotion of happiness had the highest recognition rate of the three samples at the expense of the other emotions. The facial expression of happiness tends to be better recognized probably because: 1) It may be the first (Widen \& Russell, 2003) or one of the first emotions (Durand et al., 2007) to be recognized during development, being very relevant for adaptation in the social environment, and 2) It is a positive emotion that does not need to be hidden and that occurs in interpersonal relationships more often than sadness, fear or anger (Tomkins, 1962).

The lower rate of the three groups for recognizing sadness provokes an interesting hypothesis. In the group of children, according to Gao and Maurer (2009), the difficulty in recognizing facial expressions of sadness is due to the fact that at an early age children are unable to understand typical expressions of sadness, often confusing them with the emotion of fear or simply with a neutral face. Interestingly, statistically significant positive correlations were only found in this group, indicating that age is a variable that influences the ability to recognize the facial expression of sadness.

The difficulty experienced by the children in the recognition of facial expressions of sadness contradicts the statement made by Durand et al. (2007) that says that the increase in the capacity for identifying sadness expressions occurs concurrently with the increase in the capacity for identifying happiness, as happiness and sadness are the first two emotions to be recognized in life. According to this concept, at approximately five or six years of age, performance in the recognition of emotions of happiness and sadness would be similar to that in adults. How then can the poor performance of children in recognizing the emotion of sadness be explained? One hypothesis is that they would have performed better if the emotions presented were depicted using the faces of children as models.

We failed to find studies that used databases of photographs compatible with the age of the study sample, regarding both the children and the elderly people. However, the Child Affective Facial Expression Set (CAFE), a bank of stimuli with photographs of more than 100 children, between 4 and 6 years of age, with facial expressions of happiness, anger, fear, surprise, disgust and neutral is under construction. Cat Thrasher (2011) and Vanessa LoBue are constructing this database (for more information: access http://www.catthrasher. com/child-affective-facial-expression-set/) that will 
facilitate future clarification of how the infant perception responds to stimuli consistent with their age group.

Emotions of fear, anger and sadness had a similar recognition rate in the young adults and the elderly people, suggesting difficulty to distingue these expressions. In fact, many expressions of fear were classified as anger and vice-versa. This misclassification of negative emotion expressions can be explained as being due to developmental factors. In the case of children, they are still developing the capacity for recognition of these negative emotions, and the decline showed by the elderly people may be due to the aging process and possible cognitive impairment.

Therefore, the differences found in the performance of children versus young adults reveal that the development of the ability to recognize emotions is still maturing. Furthermore, the children presented a lower performance than the young adults in the perception of emotional expressions at low intensities. According to Gao et al. (2010), the immaturity of the child's visual system can restrict the sensitivity to recognize emotions at low intensities, causing subtle emotions to be interpreted as ambiguous. This is supported by positive correlations found between the age of the child and the overall performance, and between the age of the child and the recognition of emotions at low intensity, suggesting that, in fact, the recognition of emotions in children improves over time.

We found that the elderly people presented a similar performance to the children regarding the recognition of emotions. These results agree with the hypothesis of the recognition ability declining with age. However, it is likely that the performance of the elderly people compared with the young adults may be due to specific characteristics of the study sample, since institutionalized elderly people tend to have greater cognitive impairments, which could be reflected in the facial expression recognition tests. Furthermore, the elderly group showed higher standard deviations in the recognition rates, which may be related to greater heterogeneity of social dynamics and economic conditions prior to institutionalization. It is interesting to observe that the losses that occur with aging do not appear to be restricted to the cognitive field, but also affect the recognition of facial expressions and hence the appraisal of important aspects of the social environment (Ekman, 1999).

\section{Final Considerations}

Throughout life, the ability to accurately recognize emotional stimuli becomes the key to successful social functioning, contributing to the promotion of mental health and well-being. The present work constitutes an initial study to expand the understanding of this important skill for social interaction. Future studies, which may involve a more systematic evaluation of cognitive functions in non-institutionalized elderly people or the use photographs compatible with participant's age, will help to clarify the issues raised by this study.

\section{References}

Biele C., \& Grabowska A. (2006). Sex differences in perception of emotion intensity in dynamic and static facial expressions. Experimental Brain Research, 171(1), 1-6.

Cat Thrasher. (2011). Child affective facial expression set. Retrived February 22, 2013, from <http://www. catthrasher.com/child-affective-facial-expression-set/>.

Durand, K., Gallay, M., Seigneuric, A., Robichon, F., \& Baudouin, J. Y. (2007). The development of facial emotion recognition: The role of configural information. Journal of Experimental Child Psychology, 97(1), 14-27.

Ebner, N. C., \& Johnson, M. K. (2009). Young and older emotional faces: Are there age-group differences in expression identification and memory? Emotion, 9(3), 329-339.

Ekman, P. (1999). Facial expressions. In T. Dalgleish \& T. Power (Eds.), The handbook of cognition and emotion (pp.301-320). Sussex: John Wiley \& Sons.

Farah, M. J., Tanaka, J. W., \& Drain, H. M. (1995). What causes the face inversion effect? Journal of Experimental Psychology: Human Perception and Performance, 21(3), 628-634.

Fox, J. (2001) Identifying emotions in faces: A developmental study. Washington, DC: Intel Science Talent Search. Retrieved October 2009, from <http://psych.nyu.edu/ pelli/docs/JeremyFoxIntel.pdf $>$.

Gao, X., \& Maurer, D. (2009). Inuence of intensity on children's sensitivity to happy, sad, and fearful facial expressions. Journal of Experimental Child Psychology, 102(4), 503-521.

Gao, X., Maurer, D., \& Nishimura, M. (2010). Similarities and differences in the perceptual structure of facial expressions of children and adults. Journal of Experimental Child Psychology, 105(1-2), 98-115.

Grady, C. L., Hongwanishkul, D., Keightley, M., Lee, W., \& Hasher, L. (2007). The effect of age on memory for emotional faces. Neuropsychology, 21(3), 371-380. 
Herba, C., \& Phillips, M. L. (2004). Annotation: Development of facial expression recognition from childhood to adolescence: Behavioural and neurological perspectives. Journal of Child Psychology and Psychiatry and Allied Disciplines, 45(7), 1-14.

Isaacowitz, D. M., Loeckenhoff, C., Wright, R., Sechrest, L., Riedel, R., Lane, R. A., et al. (2007). Age differences in recognition of emotion in lexical stimuli and facial expressions. Psychology and Aging, 22(1), 147-159.

Keightley, M. L., Chiew, K. S., Winocur, G., \& Grady, C. L. (2007). Age-related differences in brain activity underlying identification of emotional expressions in faces. Social Cognitive and Affective Neuroscience, 2(4), 292-302.

Ko, S. G., Lee, T. H., Yoon, H. Y., Kwon, J. H., \& Mather, M. (2011). How does context affect assessments of facial emotion? The role of culture and age. Psychology and Aging, 26(1), 48-59.

Maurer, D., Le Grand, R., \& Mondloch, C. J. (2002). The many faces of configural processing. Trends in Cognitive Sciences, 6(6), 255-260.

Nelson, C. A. (2001). The development and neural bases of face recognition. Infant and Child Development, 10(1-2), 3-18.

Palermo, R., \& Coltheart, M. (2004). Photographs of facial expression: Accuracy, response times, and ratings of intensity. Behavior Research Methods, Instruments \&
Computers: Special Issue on Electronic Archiving, 36(4), 634-638.

Thomas, L. A., De Bellis, M. D., Graham, R., \& LaBar, K. S. (2007). Development of emotional facial recognition in late childhood and adolescence. Developmental Science, 10(5), 547-558.

Tomkins, S. S. (1962). Affect, imagery, consciousness: The positive affects (Vol. 1). New York: Springer.

Tottenham, N., Borscheid, A., Ellertsen, K., Marcus, D. J., \& Nelson, C. A. (2002). Categorization of facial expressions in children and adults: Establishing a larger stimulus set. Journal of Cognitive Neuroscience, 14(Suppl.), S74.

Valentine, T. (1988). Upside-down faces: A review of the effects of inversion upon face recognition. British Journal of Psychology, 79(4), 471-491.

Widen, S. C., \& Russell, J. A. (2003). A closer look at preschoolers' freely produced labels for facial expressions. Developmental Psychology, 39(1), 114-128.

Zebrowitz, L. A., \& Montepare, J. M. (2008). Social psychological face perception: Why appearance matters. Social and Personality Psychology Compass, 2(3), 1497-1517.

Received on: 19/11/2010

Final version on: 28/3/2012

Approved on: 24/4/2012 
